\title{
PENGELOLAAN SAMPAH PLASTIK MENJADI PAVING BLOCK SEBAGAI PROSPEK BISNIS PADA MASYARAKAT PRA SEJAHTERA
}

\section{MANAGEMENT OF PLASTIC WASTE TO PAVING BLOCK AS A BUSINESS PROSPECT IN PRE-PROSPEROUS COMMUNITIES}

\author{
Mukhtar Abdul Kader*, Elin Herlina, Wiwin Setianingsih \\ Program Studi Manajemen Fakultas Ekonomi Universitas Galuh \\ Jalan RE. Martadina No. 150, Kecamatan Baregbeg Kabupaten Ciamis \\ *Email: mwrd7380@gmail.com \\ (Diterima 14-01-2021; Disetujui 08-03-2021)
}

\begin{abstract}
ABSTRAK
Pengelolaan sampah plastik bersama masyarakat, proses dan pengelolaanya menjadi paving block hingga produk ini mampu menjadi suatu bagian dari wirausaha baru yang layak untuk dijalankan hingga dapat merubah dan menambah pendapatan masyarakat prasejahtera. Target utama dalam pengabdian ini adalah masyarakat prasejahtera di Desa Sukaraja, dimana berdasarkan Database Desa Sukaraja jumlah masyarakat prasejahtera berjumlah 1.446 atau $25 \%$ jumlah penduduk 6.112 orang. Metode untuk mencapai target dengan menggunakan model Technical Assistence dalam bentuk Training dan Pendampingan. Metode ini sangat efektif digunakan mengingat masyarakat sebagai target merupakan masyarakat prasejahtera sangat memerlukan hubungan kedekatan dan tingkat kesabaran yang tinggi sekaligus memiliki motivasi untuk merubah dan menambah penghasilan. Pelaksanaan kegiatan mulai dari persiapan, pelaksanaan sampai dengan pelaporan yaitu melaksanakan workshop dan Pendampingan proses dan pengelolaan sampah plastik menjadi produk paving block; dengan cara: (1) Oleskan oli pada tanki peleburan sampah lalu masukan sampah plastik ringan ke dalam tanki. (2) Panaskan sampah-sampah tersebut sampai melebur rata, jika telah lebur dengan merata tambahkan sampah residu dan beri sedikit oli lalu aduk lagi sampai merata. (3) Jika adonan sampah telah lebur secara merata campurkan lebu dengan perbandingan takaran $1: 1$ dan aduk hingga merata. (4) Masukan sampah yang sudah melebur rata tersebut ke dalam cetakan paving block lalu diratakan dengan menggunakan sendok semen. (5) Setelah adonan merata lalu press ke dalam cetakan yang sudah tersedia, disiramkan sedikit menggunakan air agar tidak panas. (6) Sesudah dipress kemudia dimasukan ke dalam loyang yang telah disi dengan air. (7) Didiamkan adonan yang telah dipress, lalu diangkat dan dijadikan sebuah paving block plastik yang kuat. Kelayakan Bisnis sampah plastik paving block dengan Payback Periode 1.22 tahun, Net Presnt Value positif 129.130.707 dan Profitability Index 2,22.
\end{abstract}

Kata Kunci : Sampah Plastik,Paving Block,Prospek Bisnis Sampah Plastik,Masyarakat Pra Sejahtera

\section{ABSTRACT}

The management of plastic waste together with the community, processes and its management into paving blocks so that this product is able to become a part of a new entrepreneurship that is feasible to run so that it can change and increase the income of underprivileged people. The main target in this service is the underprivileged people in Sukaraja Village, where based on the Sukaraja Village Database the number of underprivileged people is 1,446 or 25\% of the total population of 6,112 people. The method for achieving the target is using the Technical Assistence model in the form of Training and Assistance. This method is very effective to use considering that the target community is an underprivileged community who really need a close relationship and a high level of patience as well as having the motivation to change and increase income. The implementation of activities ranging from preparation, implementation to reporting, namely carrying out workshops and assistance in the process and management of plastic waste into paving block products. By: (1). Apply oil to the waste melting tank then put light plastic waste into the tank. (2) Heat the rubbish until it melts evenly, if it has melted evenly, add the residual waste and add a little oil then stir again until evenly distributed. (3). If the garbage dough has melted evenly, mix the sugarcane with a 1: 1 ratio and stir until evenly distributed. (4). Put the melted waste into the paving block mold then flatten it using a cement spoon. (5). After the dough is evenly distributed, then press it into the available mold, pour it a little with water so it doesn't heat up. (6). After pressing it, enter it into the pan that has been filled with water. (7). Leave the dough that has been pressed then lift it and make a strong plastic paving block. Business Feasibility of paving block plastic waste with a payback period of 1.22 years, positive Net Presnt Value 129.130.707 and Profitability Index 2.22

Keywords: Plastic Waste, Paving Block, Plastic Waste Business Prospects, Pre-Prosperous Community 


\section{PENDAHULUAN}

Plastik merupakan material yang sangat sulit terurai dimana degradasi plastik dengan cara penimbunan memakan waktu yang sangat lama hingga puluhan tahun. Di Indonesia konsumsi plastik juga meningkat dengan cepat. Penggunaan plastik akan terus meningkat karena adanya peningkatan populasi manusia, perkembangan aktivitas serta perubahan kondisi gaya hidup dan sosio-ekonomi masyarakat. Menurut Sekjen Asosiasi Industri Olefin, Aromatik, dan Plastik Indonesia (Inaplas), konsumsi plastik terus mengalami pertumbuhan dari peningkatan konsumsi sebesar 4,5 juta ton pada tahun 2015 meningkat menjadi 4,8 juta ton pada tahun 2016, atau tumbuh sebesar 5,2\% (Berita Industri, 2016).

Peningkatan konsumsi ini terutama didorong oleh pertumbuhan industri makanan dan minuman, dimana industri tersebut banyak menggunakan plastik untuk kemasan produknya. Konsumsi plastik ini juga akan mendorong peningkatan jumlah limbah plastik yang dihasilkan. Pada tahun 2015 total jumlah limbah padat mencapai 64,5 juta ton. Limbah tersebut berasal dari rumah tangga (48\%), pasar tradisional (24\%), jalan (7,5\%), kawasan komersial (9\%), sekolah (4\%), kantor (6\%) dan lainnya (1,5\%). Dari total limbah yang dihasilkan tersebut, $14 \%$ nya atau sekitar 8,96 juta ton merupakan limbah plastik (Anonim KLH, 2015).

Berbagai masalah dapat ditimbulkan oleh limbah plastik seperti penyumbatan saluran air dan aliran sungai sehingga menyebabkan banjir, penanganan plastik dengan cara dibakar dapat melepaskan gas beracun ke atmosfir, dan lain sebagainya. Saat ini, dari jumlah limbah plastik yang dihasilkan, hanya sekitar 5-10\% yang telah di daur ulang. Daur ulang plastik selain penting untuk mengurangi pencemaran lingkungan juga dapat digunakan untuk mencegah pemborosan sumber daya alam (Indrawijaya, 2019). Bahkan daur ulang limbah plastik dapat memberikan keuntungan ekonomi bagi masyarakat. Salah satu alternatif daur ulang plastik yang menarik adalah penggunaan limbah plastik sebagai campuran semen untuk menghasilkan komposit semen plastik dan sebagai agregat beton untuk menghasilkan bahan konstruksi (Putra \& Yuriandala, 2010). Plastik mempunyai karakteristik penting yang dapat dimanfaatkan baik secara sendiri atau komposit sebagai bahan konstruksi, yaitu seperti tahan lama, tahan korosi, isolator yang baik untuk dingin, panas, dan suara, penghematan energi, ekonomis, memiliki umur pakai yang panjang, dan ringan (Jassim, 2017)

Penggunaan plastik untuk bahan konstruksi dapat meningkatkan elastisitas dan daya tahan serta menurunkan densitas sehingga bahan menjadi lebih ringan. Selain itu, penggunaan limbah plastik juga diharapkan dapat menghasilkan bahan konstruksi dengan 
harga yang lebih murah, serta yang penting lainnya adalah adanya alternatif solusi dalam penanganan dan pemanfaatan limbah plastik guna mencegah terjadinya pencemaran lingkungan. Selain berkurangnya sampah plastik juga hasil dari paving block ini selanjutnya dapat diperjualbelikan sebagai bahan bangunan sehingga dapat membuka usaha baru bagi masyarakat terutama masyarakat pra sejahtera yang jumlahnya masih tergolong banyak dan berusia produktif. Jumlah penduduk desa sukaraja 6.112 dimana jumlah penduduk yang masuk kategori miskin berjumlah 1.448 atau 23.69\%. (Sukaraja, 2019).

\section{BAHAN DAN METODE}

Pembuatan paving block yaitu dengan komposisi yang terbuat dari campuran sampah plastik, oli, lebu tanpa bahan tambahan lainnya yang tidak mengurangi mutu paving block tersebut. Bahan berupa plastik sampah, oli bekas dan lebu. Alat berupa cetakan, wajan, press, ember, sendok semen. Metode yang digunakan dalam kegiatan ini adalah model technical assistance dalam bentuk training dan pendampingan yang dilaksanakan dengan memberikan pelatihan dalam bentuk workshop kepada masyarakat prasejahtera tentang proses Pengelolaan sampah plastik dan kelayakan bisnis produk paving block.

\section{HASIL DAN PEMBAHASAN}

\section{A. Proses dan Pengelolaan Sampah Plastik menjadi Paving Block}

Sampah merupakan masalah yang sering kita hadapi, tidak terkecuali di Desa Sukaraja. Banyak dari kegiatan rumah tangga yang menghasilkan sampah, terutama sampah plastik. Plastik banyak dipakai dalam kehidupan sehari-hari, karena mempunyai keunggulan-keunggulan seperti kuat, ringan dan stabil. Namun, plastik yang beredar di pasaran saat ini merupakan polimer sintetik yang terbuat dari minyak bumi yang sulit terurai di alam. Akibatnya semakin banyak yang menggunakan plastik, akan semakin meningkat pula pencemaran lingkungan seperti pencemaran tanah. Untuk mengatasi permasalahan tersebut terdapat alternatif pengolahan sampah plastik, yaitu mendaur ulang sampah plastik menjadi barang yang memiliki nilai guna. Hal ini dikarenakan sampah plastik memiliki kandungan air yang cukup rendah, yaitu $2 \%$ berat basah jika dibandingkan dengan jenis sampah lain. Kandungan air yang rendah pada sampah plastik memudahkan dalam proses pengolahan. Limbah plastik yang tadinya hanya sebagai barang yang dibuang, kotor, berbau, banyak menimbulkan penyakit dan mencemari lingkungan, kini dapat diolah sebagai barang yang bermanfaat serta memiliki nilai ekonomi tinggi. 
Melihat permasalahan tersebut sampah sampah tersebut akan lebih bernilai ekonomis jika sampah plastik tersebut menjadi paving block yang banyak dibutuhkan masyarakat untuk membangun rumah atau pagar halaman. Pemanfaatan limbah plastik untuk dijadikan paving block sebagai produk bernilai jual tinggi dapat memberdayakan masyarakat agar masyarakat Desa Sukaraja dapat mengolah sampah plastik yang ada di sekitar lingkungan menjadi barang dengan nilai jual yang lebih tinggi. Sampah plastik di Desa Sukaraja dapat berkurang dan para pemuda memiliki keahlian lebih untuk dapat menunjang kehidupan mereka dengan cara mengolah plastik menjadi paving block dan mengemasnya sehingga dihasilkan produk yang menarik dan memiliki nilai jual. Tahapan pembuatan paving block ini dilaksanakan dalam dua tahap yang dilakukan dalam satu hari. Tahapan pertama yaitu dengan memberi penyuluhan kepada para pemuda Desa Sukaraja yang dilaksanakan di GOR Desa Sukaraja. Tahapan kedua yaitu praktik cara pembuatan paving block dari bahan plastik hingga paving block memiliki manfaat dan memiliki nilai jual. Paving block dapat dimanfaatkan untuk menutup permukaan tanah pada halaman rumah, jalan setapak, maupun taman. Selain itu, paving block ini dapat menambah nilai estetika suatu tempat. Hal ini dikarenakan paving block ini dapat dimodifikasi dengan warna-warna yang menarik.

Cara pembuatan: (1). Oli dioleskan pada tanki peleburan sampah lalu dimasukan sampah plastik ringan ke dalam tanki. (2) Sampah-sampah tersebut dipanaskan sampai melebur rata, jika telah lebur dengan merata ditambahkan sampah residu dan diberi sedikit oli lalu diaduk lagi sampai merata. (3). Jika adonan sampah telah lebur secara merata, selanjutnya dicampurkan lebu dengan perbandingan takaran 1:1 dan diaduk hingga merata. (4). Sampah yang sudah melebur rata tersebut dimasukan ke dalam cetakan paving block lalu diratakan dengan menggunakan sendok semen. (5). Setelah adonan merata lalu dipress ke dalam cetakan yang sudah tersedia, disiramkan sedikit menggunakan air agar tidak panas. (6). Sesudah dipress lalu dimasukan ke dalam loyang yang telah disi dengan air. (7). Didiamkan adonan yang telah dipress lalu diangkat dan dijadikan sebuah paving block plastik yang kuat. 


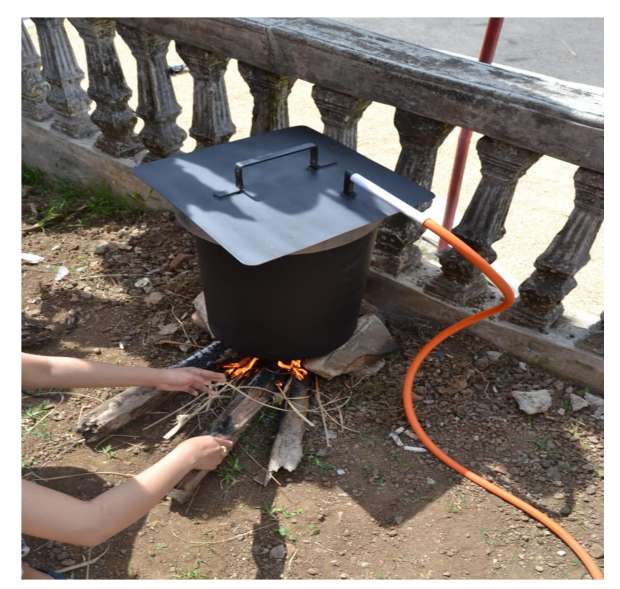

Gambar 1. Pemanasan tungku

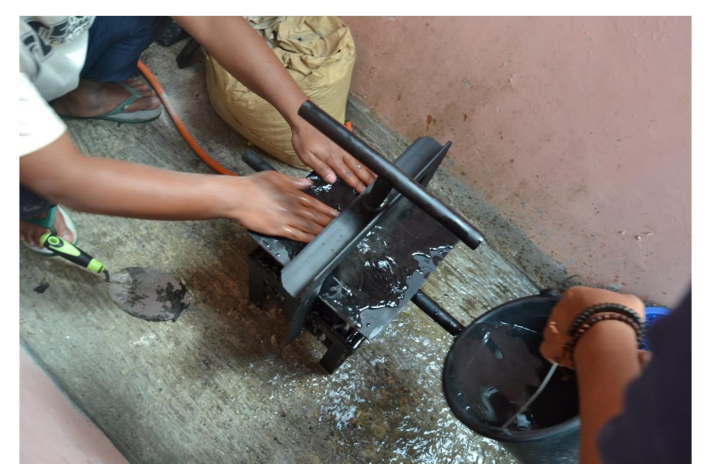

Gambar 3. Pendinginan cetakan

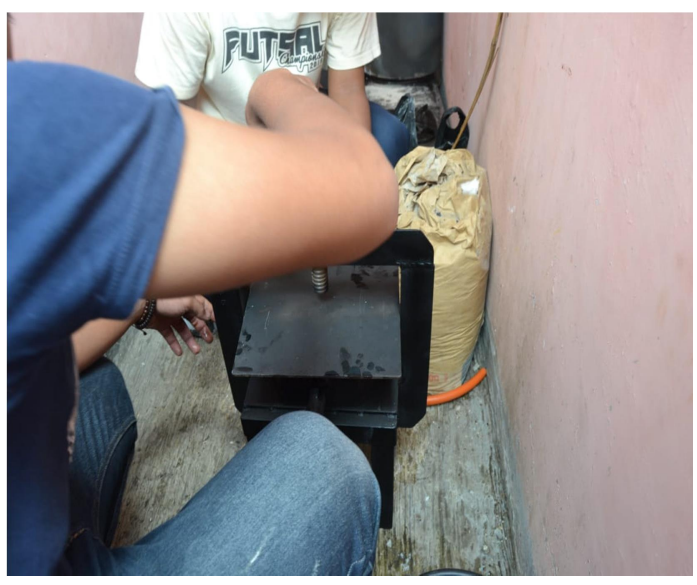

Gambar 2. Pengepresan campuran plastik

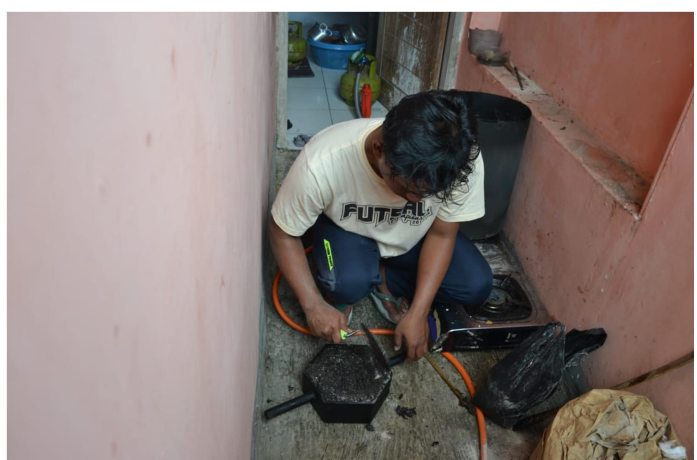

Gambar 4. Pelepasan paving block dari cetakan

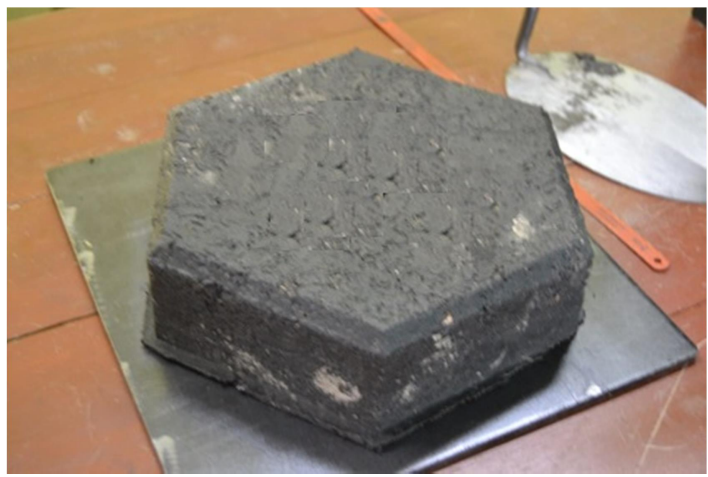

Gambar 5. Hasil Olahan Plastik menjadi Pavimblok

Kelebihan dari pembuatan paving block dari bahan sampah plastik yaitu lebih kuat dan tahan banting. Kelebihan tersebut telah dibuktikan dengan uji coba yang dilakukan dengan menggunakan mobil. Dalam proses uji coba tersebut pengendara diminta untuk menglintasi paving block plastik. Setelah uji coba berhasil terbukti bahwa paving block plastik tidak hancur meskipun telah dilintasi mobil. Paving block yang terbuat dari sampah plastik lebih kuat dan tidak akan terbelah ketika dilemparkan ke bawah dengan kencang. Berbeda dengan yang terbuat dari semen, jika dilemparkan dengan kencang maka paving block dari semen tersebut akan terbelah. 


\section{B. Kelayakan Bisnis Produk Paving Block Plastik}

Dalam melaksanakan analisis kelayakan bisnis dari pembuatan paving block model Hexagon perlu diketahui nilai investasinya, Cash Flow, Discount Factor, Total Revenue, Total Cost, Harga per unit dan variable cost. Pembuatan paving block plastik dimulai dari pengumpulan plastik diakhiri dengan proses mendinginkan produk ke dalam air. Model hexagonal dalam satu meter menggunakan 27 Pcs, Setiap satu paving block membutuhkan sekitar $1 / 2 \mathrm{~kg}$ sampah plastik. Jadi, dengan satu meter persegi tersebut telah menyingkirkan 13,5 kg sampah plastik dari lingkungan. Produk ini masih lebih mahal daripada paving block konvensional. Jika harga paving block di pasaran bervariasi antara Rp80 ribu-Rp130 ribu, paving block ini berada pada kisaran harga Rp150 ribu-Rp160 ribu per meter lebih mahal sekitar -30\%-35\% dibandingkan dengan paving block biasa.

Meski memiliki beberapa kelemahan dibanding paving block biasa, dampak lingkungan yang dihasilkan membuat produk tersebut pantas menjadi salah satu solusi pengurangan sampah plastik. Selain itu, kita berharap bisa merubah pola fikir masyarakat terhadap sampah plastik sehingga dapat merubah prilaku masyarakat dapat memisahkan sampah plastik dan sampah lainnya atau yang biasa disebut organik dan anorganik. Bahan bahan yang perlu disiapkan adalah sebagai berikut: tank, cetakan, alat press, sendok semen, selang, lebu, dan bahan bahan lainya. Berikut analisis kelayakan bisnis dari produk paving blok plastik tersebut per 1 meter persegi dengan 5 mesin selama satu bulan (satu bulan dianggap 25 hari), Masing-masing mesin per hari permeter.

Tabel 1 Bahan-bahan Pembuatan Paving Block Periode 1 Tahun

\begin{tabular}{|c|c|c|c|}
\hline Bahan-bahan & Biaya / Unit & Jumlah & Total \\
\hline Tank & 300,000 & 2 & 600,000 \\
\hline Cetakan & 600,000 & 10 & $6,000,000$ \\
\hline Alat press & 700,000 & 10 & $7,000,000$ \\
\hline Sendok semen & 25,000 & 2 & 50,000 \\
\hline Selang & 75,000 & 10 & 750,000 \\
\hline Lebu & 10,000 & 10 & 100,000 \\
\hline Bahan Lainnya & 300,000 & 10 & $3,000,000$ \\
\hline \multicolumn{3}{|c|}{ Jumlah } & 17.500 .000 \\
\hline
\end{tabular}


Tabel 2 Biaya Tetap dan Biaya Variabel Periode 1 Tahun

\begin{tabular}{|c|c|c|c|}
\hline No. & Item Pembiayaan & Biaya Tetap & Biaya Variabel \\
\hline 1 & Gaji Pegawai & 48.000 .000 & \\
\hline 2 & Asuransi & 1.800 .000 & \\
\hline 3 & Penyusutan Peralatan & 4.800 .000 & \\
\hline 4 & Sewa Tempat & 6.000 .000 & \\
\hline 5 & Bahan Baku & & 24.000 .000 \\
\hline 6 & Tenaga Kerja Langsung & & 1.200 .000 \\
\hline 7 & Lain-lain & & 2.400 .000 \\
\hline & Jumlah & 36.600 .000 & 4.000 .000 \\
\hline
\end{tabular}

\section{Analisis Kelayakan Bisnis Produk Paving Block Plastik}

Analisis kelayakan bisnis dari produk paving block minimal menggunakan 3 jenis analisis dengan harapan ada pembanding jika terdapat dua analisis hasilnya sama. Alat analisis yang digunakan adalah Payback Periode, Net Present Value dan Profitability Index. Ketiga analisis tersebut saling berkaitan namun demikian untuk mengawali analisis kita harus memiliki terlebih dahulu laporan keuangan yaitu EAT (Earning After Tax) yaitu laporan keuangan Laba Bersih Setelah Pajak. Analisis kelayakan bisnis dari pembuatan produk Paving block di prediksikan selama 4 tahun. Berikut analisisnya:

\section{A. Sumber Dana}

Sumber dana yang dibutuhkan terlebih dahulu memaparkan kebutuhan keuangan dalam satu tahun. Berikut penjelasannya.

Tabel 3 Perhitungan Jumlah Modal yang Dibutuhkan

\begin{tabular}{|c|c|c|c|c|c|}
\hline \multicolumn{2}{|c|}{ Sumber Dana } & \multicolumn{4}{|c|}{ Penggunaan Dana } \\
\hline Modal Sendiri & 105.700 .000 & Bahan-bahan & Biaya/Unit & Jumlah & Total \\
\hline & & Tank & 300.000 & 2 & 600.000 \\
\hline & & Cetakan & 600.000 & 10 & 6.000 .000 \\
\hline & & Alat press & 700.000 & 10 & 7.000 .000 \\
\hline & & Sendok semen & 25.000 & 2 & 50.000 \\
\hline & & Selang & 75.000 & 10 & 750.000 \\
\hline & & Lebu & 10.000 & 10 & 100.000 \\
\hline & & Bahan Lainnya & 300.000 & 10 & 3.000 .000 \\
\hline & & Gaji Pegawai & 4.000 .000 & 12 & 48.000 .000 \\
\hline & & Asuransi & 150.000 & 12 & $1,800.000$ \\
\hline & & Penyusutan Peralatan & 400.000 & 12 & $4,800.000$ \\
\hline & & Sewa Tempat & 500.000 & 12 & $6,000.000$ \\
\hline & & Bahan Baku & 80.000 & 300 hari & 24.000 .000 \\
\hline & & Tenaga Kerja Langsung' & 100.000 & 12 & 1.200 .000 \\
\hline & & Lain-lain Biaya & 200.000 & 12 & 2.400 .000 \\
\hline Total & 105.700 .000 & & & Total & 105.700 .000 \\
\hline
\end{tabular}




\section{B. Pendapatan dalam Setahun}

Pendapatan dalam satu tahun diperoleh sebelumnya menghitung pendapatan dalam satu bulan dengan kekuatan 5 mesin dengan kapasitas 1 meter per mesin per hari selama 25 hari kerja, dan selanjutnya dengan memprediksi tingkat kegagalan 2 tahun pertama 15\% dan tahun ketiga dan ke empat $20 \%$

Tabel 4 Pendapatan Dalam 1 tahun

\begin{tabular}{|c|c|l|r|r|r|}
\hline Jumlah Hari (sebulan) & Mesin & Kapasitas/hari & $\begin{array}{c}\text { Harga Jual / } \\
\text { Meter }\end{array}$ & Pend/ hari & Pendapatan/Bulan \\
\hline 25 & 5 & $\begin{array}{l}1 \text { meter } \\
\text { per meter 150000 }\end{array}$ & 150,000 & 750,000 & $18,750,000$ \\
\hline
\end{tabular}

Penerimaan Pendapatan
\begin{tabular}{|l|r|r|r|r|}
\hline \multicolumn{1}{|c|}{ Keterangan } & Tahun Ke-1 & Tahun Ke-2 & \multicolumn{1}{|c|}{ Tahun Ke-3 } & \multicolumn{1}{c|}{ Tahun Ke-4 } \\
\hline Penerimaan pertahun & $225,000,000$ & $225,000,000$ & $225,000,000$ & $225,000,000$ \\
\hline Faktor Perkalian & $85 \%$ & $85 \%$ & $80 \%$ & $80 \%$ \\
\hline Total Penerimaan & $\mathbf{1 9 1 , 2 5 0 , 0 0 0}$ & $\mathbf{1 9 1 , 2 5 0 , 0 0 0}$ & $\mathbf{1 8 0 , 0 0 0 , 0 0 0}$ & $\mathbf{1 8 0 , 0 0 0 , 0 0 0}$ \\
\hline
\end{tabular}

\section{Biaya-biaya}

Total Biaya yang digunakan adalah total biaya operasional dan biaya depresiasi, biaya depresiasi menggunakan rumus SYD (Sum of Year's Digits) oleh karena pendapatan tiap tahunnya tidak sama, berikut rinciannya:

1. Biaya Operasional

Tabel 5 Biaya Operasional

\begin{tabular}{lrrrr}
\hline Rincian Pembiayaan & Tahun Ke-1 & Tahun Ke-2 & Tahun Ke-3 & Tahun Ke-4 \\
\hline Gaji Karyawan & $48,000,000$ & $48,000,000$ & $48,000,000$ & $48,000,000$ \\
Asuransi & $1,800,000$ & $1,800,000$ & $1,800,000$ & $1,800,000$ \\
Sewa Tempat & $6,000,000$ & $6,000,000$ & $6,000,000$ & $6,000,000$ \\
Bahan Baku & $24,000,000$ & $24,000,000$ & $24,000,000$ & $24,000,000$ \\
Upah Kerja & $1,200,000$ & $1,200,000$ & $1,200,000$ & $1,200,000$ \\
Perawatan Mesin & $12,000,000$ & $12,000,000$ & $12,000,000$ & $12,000,000$ \\
Lain lain Biaya & $2,400,000$ & $2,400,000$ & $2,400,000$ & $2,400,000$ \\
Depresiasi & $5,200,000$ & $3,900,000$ & $2,600,000$ & $1,300,000$ \\
\hline Total Biaya & $100,600,000$ & $99,300,000$ & $98,000,000$ & $96,700,000$ \\
\hline
\end{tabular}

D. Depresiasi dengan menggunakan SYD (Sum of Year's Digits)

\begin{tabular}{|l|r|r|}
\hline Jumlah mesin & 10 & \\
\hline Harga Per unit & $1,300,000$ & \\
\hline Total Harga Mesin & $13,000,000$ & \\
\hline Nilai S isa & - & \\
\hline Umur Ekonomis & 4 & Tahun \\
\hline & & 1 \\
\hline Depresiasi & $5,200,000$ & 2 \\
\hline & $3,900,000$ & 3 \\
\hline & $2,600,000$ & 4 \\
\hline
\end{tabular}




\section{E. EAT (Earning After Tax)}

Earning After tax adalah laba yang di peroleh setelah pajak, biasa disebut pendapatan bersih, EAT di peroleh dari pendapatan kotor dikurangkan dengan pajak.

Tabel 6 Laba Bersih Tahun ke 1 s.d. Tahun ke 4

\begin{tabular}{|l|r|r|r|r|}
\hline \multicolumn{1}{|c|}{ Uraian } & Tahun Ke -1 & Tahun Ke -2 & Tahun Ke -3 & Tahun Ke -4 \\
\hline A. Pendapatan & $191,250,000$ & $191,250,000$ & $180,000,000$ & $180,000,000$ \\
\hline B. Biaya & & & & \\
\hline - Gaji Karyawan & $48,000,000$ & $48,000,000$ & $48,000,000$ & $48,000,000$ \\
\hline - Asuransi & $1,800,000$ & $1,800,000$ & $1,800,000$ & $1,800,000$ \\
\hline - Sewa Tempat & $6,000,000$ & $6,000,000$ & $6,000,000$ & $6,000,000$ \\
\hline - Bahan Baku & $24,000,000$ & $24,000,000$ & $24,000,000$ & $24,000,000$ \\
\hline - Upah Kerja & $1,200,000$ & $1,200,000$ & $1,200,000$ & $1,200,000$ \\
\hline - Perawatan Mesin & $12,000,000$ & $12,000,000$ & $12,000,000$ & $12,000,000$ \\
\hline - Lain lain Biaya & $2,400,000$ & $2,400,000$ & $2,400,000$ & $2,400,000$ \\
\hline - Depresiasi & $5,200,000$ & $3,900,000$ & $2,600,000$ & $1,300,000$ \\
\hline Total & $100,600,000$ & $99,300,000$ & $98,000,000$ & $96,700,000$ \\
\hline C. Laba Kotor & $90,650,000$ & $91,950,000$ & $82,000,000$ & $83,300,000$ \\
\hline D. Pajak 10\% & $9,065,000$ & $9,195,000$ & $8,200,000$ & $8,330,000$ \\
\hline E. Laba Bersih & $81,585,000$ & $82,755,000$ & $73,800,000$ & $74,970,000$ \\
\hline
\end{tabular}

\section{a. Payback Period (PP)}

Payback Period adalah metode yang mendasarkan pada jumlah tahun yang diperlukan untuk mengembalikan investasi awal. Kelemahan metode ini adalah (1) mengabaikan penerimaan setelah payback tercapai, (2) mengabaikan konsep time value of money. Payback Period adalah suatu periode yang diperlukan untuk dapat menutup kembali pengeluaran investasi dengan menggunakan proceed atau aliran kas neto (net cash flow). Berikut cara menentukan berapa waktu yang dibutuhkan untuk mengembalikan modal yang digunakan.

Tabel 7 Menentukan Payback Periode

\begin{tabular}{|c|c|c|c|c|c|}
\hline \multicolumn{3}{|c|}{ Nilai Investasi } & $105,700,000$ & & \\
\hline Tahun & EAT & Depresiasi & Cash Flow & & \\
\hline 1 & $81,585,000$ & $5,200,000$ & $86,785,000$ & & \\
\hline 2 & $82,755,000$ & $3,900,000$ & $86,655,000$ & & \\
\hline 3 & $73,800,000$ & $2,600,000$ & $76,400,000$ & & \\
\hline 4 & $74,970,000$ & $1,300,000$ & $76,270,000$ & & \\
\hline Rata-rata & $78,277,500$ & $3,250,000$ & $81,527,500$ & & \\
\hline \multicolumn{3}{|c|}{ Nilai Investasi } & $105,700,000$ & Sisa & \\
\hline \multicolumn{3}{|c|}{ Cash Infow Th Ke 1} & $86,785,000$ & $18,915,000$ & \\
\hline \multirow{2}{*}{\multicolumn{3}{|c|}{ Cash Infow Th Ke 2}} & $86,655,000$ & $(67,740,000)$ & Kelebihan \\
\hline & & & & 9.38 & Kelebihan Bulan \\
\hline \multicolumn{3}{|c|}{ Payback Periode } & 1.22 & Tahun & \\
\hline
\end{tabular}


Dari hasil analisis diperoleh payback period sebesar 1.22 artinya modal usaha dapat dikembalikan dalam waktu 1 tahun 2 bulan. Waktu pengembalian modal semakin cepat semakin bagus.

\section{b. Net Present Value (NPV)}

NPV merupakan salah satu teknik Capital Budgeting yang banyak digunakan, oeh karena metode ini mempertimbangkan nilai waktu uang, Net Present Value dapat dihitung dengan formula NPV=Present Cash Inflow-Nilai Investasi, sehingga NPV merupakan selisih antara capital inflow yang didiskontokan pada tingkat bunga minimum atau pada tingkat bunga cost of capital perusahaan dikurangi dengan nilai investasi. Berikut diperoleh hasil perhitungan NPV dari kasus di atas sebagai berikut:

Tabel 8 Perhitungan Net Present Value

\begin{tabular}{|c|c|c|c|}
\hline \multicolumn{3}{|c|}{ Nilai Investasi } & $105,700,000$ \\
\hline \multicolumn{3}{|c|}{ Tingkat Bunga } & $15 \%$ \\
\hline Tahun & Cash Inflow & Discount Factor & Present Value \\
\hline 1 & $86,785,000$ & 0.869565 & $75,465,217.39$ \\
\hline 2 & $86,655,000$ & 0.756144 & $65,523,629.49$ \\
\hline 3 & $76,400,000$ & 0.657516 & $50,234,240.16$ \\
\hline \multirow[t]{2}{*}{4} & $76,270,000$ & 0.571753 & $43,607,620.04$ \\
\hline & \multicolumn{2}{|c|}{ Present Cash Inflow } & $234,830,707.08$ \\
\hline \multicolumn{3}{|c|}{ Net Present Value Adalah } & $129,130,707$ \\
\hline
\end{tabular}

Dari perhitungan tersebut di peroleh NPV $=129.130 .707$ dan bernilai positif, jika bernilai positif maka kegiatan produk paving block layak untuk di terima.

\section{c. Profitability Index (PI)}

Profitability Index digunakan dalam menghitung perbandingan antara nilai arus kas bersih yang akan datang dengan nilai investasi yang sekarang. Profitability Index harus lebih besar dari 1 baru dikatakan layak. Semakin besar PI, investasi semakin layak. Kelayakan investasi menurut standar analisa ini adalah: Jika PI $>1$; maka investasi tersebut dapat dijalankan dan Jika PI $<1$; investasi tersebut tidak layak dijalankan.

Dari perhitungan tersebut di peroleh Profitability index sebesar 2.22, sesuai dengan standar kelayakan dari PI tersebut maka dinyatakan bahwa Bisnis paving Block Plastik layak untuk di jalankan 
Tabel 9 Perhitungan Profitability Index

\begin{tabular}{l} 
Nilai Investasi \\
Tingkat Bunga \\
\begin{tabular}{|c|r|r|r|}
\cline { 2 - 3 } Tahun & Cash Inflow & Dis count Factor & Prese nt Value \\
\hline 1 & $86,785,000$ & 0.869565 & $75,465,217.39$ \\
\hline 2 & $86,655,000$ & 0.756144 & $65,523,629.49$ \\
\hline 3 & $76,400,000$ & 0.657516 & $50,234,240.16$ \\
\hline 4 & $76,270,000$ & 0.571753 & $43,607,620.04$ \\
\hline \multicolumn{3}{|c|}{ Present Cash Inflow } & $234,830,707.08$ \\
\hline
\end{tabular} \\
\hline
\end{tabular}

\section{KESIMPULAN DAN SARAN}

Berdasarkan hasil penelitian tersebut di atas pada masyarakat prasejahtera di desa Sukaraja Kecamatan Sindangkasih, pengabdi memberikan kesimpulan sebagai berikut: (1). Proses dan pengelolaan sampah plastik menjadi paving block dilakukan secara teratur dan terstruktur mulai dari menyediakan bahan bahan dan alat alat proses pembuatan, sedangkan proses pembuatan dimulai dari mengoleskan oli pada tanki peleburan sampah, pembakaran sampah sampai melebur rata, ditambahkan sampah residu, diberikan sedikit oli dan diaduk sampai merata, dicampurkan lebu dengan perbandingan takaran 1:1, dimasukan sampah yang sudah melebur rata ke dalam cetakan paving block kemudian diratakan dengan menggunakan sendok semen, dipress ke dalam cetakan, disiramkan sedikit air agar tidak panas, dimasukan ke dalam loyang yang telah disi dengan air, didiamkan adonan sampai diperkirakan sudah dingin, jadilah 1 buah paving block yang kuat. (2). Kelayakan bisnis produk paving block plastik, dengan menggunakan 3 jenis analisis yakni Payback Periode, Net Present Value dan Profitability Index. Payback Period diperoleh 1,22 tahun artinya modal dapat dikembalikan selama proses produksi berjalannya perusahaan selama 1,2 tahun. Net Present Value diperoleh angka positif sebesar 129,130,707 artinya jika NPV positif maka layak untuk diteruskan atau dikembangkan, sedangkan profitability Indeks menunjukkan angka 2,22. Jika PI menunjukkan angka di atas 1 maka layak untuk diteruskan atau dikembangkan. Pengelolaan sampah terutama sampah plastik di Desa Sukaraja sudah selayaknya dikembangkan terus oleh masyarakat, selain mengurangi input sampah plastik juga dapat menambah pendapatan masyarakat dari hasil mengubah sampah tersebut menjadi paving block.

Saran yang diajukan adalah sebagai berikut: Untuk mempermudah pengumpulan sampah plastik setiap rumah disediakan wadah tempat pengumpulan plastik dan mudah 
diangkut ke tempat pengolahan, Menciptakan alat cetak/alat pengolahan sampah plastik yang jumlahnya lebih banyak, Pengelolaan sampah plastik ditempatkan di satu tempat pada lahan yang agar jauh dari masyarakat, oleh karena selain berserakan, juga pada saat proses pembakaran menimbulkan bau plastik. Paving block hasil produksi agar digunakan dulu oleh masyarakat Desa Sukaraja sebagai contoh masyarakat lainnya, Pengolahan sampah plastik sebaiknya dikelola oleh desa dengan melibatkan masyarakat prasejahtera.

\section{UCAPAN TERIMA KASIH}

Kami ucapkan terima kasih kepada yang terhormat Kepala Desa Sukaraja dan seluruh masyarakat terutama para pemuda yang sudah membantu dan berpartisipasi mengkoordinasikan masyarakat prasejahtera di desa Sukaraja Kabupaten Ciamis.

\section{DAFTAR PUSTAKA}

Ahmann, D \& Dorgan J. R., 2009. Bioengineering for Pollution Prevention through Development of Biobased Energy and Materials State of the Science Report, EPA/600/R-07/028. p.76-78.

Anonim. 2010. Bagaimana Biologi Dipelajari. Tersedia: http://materi-pelajaranbiologi.blogspot.com/2010/06/bagaimana-biologi-ipelajari.html,diakses pada Jum'at 18 Oktober 2013.

Anonim.(2015).Wisatatamanhutanjayagiri.Tersedia[Online]:

http://www.easytourbandung.com/2015/02/wisata-taman-hutan-jayagirilembang.html (Diakses pada 1 Maret 2018)

Fahmi, Irham. 2014. Analisis LaporaN Keuangan, Bandung : Alfabeta

Indrawijaya, B. (2019). Pemanfaatan Limbah Plastik Ldpe Sebagai Pengganti Agregat Untuk Pembuatan Paving Blok Beton. Jurnal Ilmiah Teknik Kimia, 3(1), 1-7. https://doi.org/10.32493/jitk.v3i1.2594

Jassim, A. K. (2017). Recycling of Polyethylene Waste to Produce Plastic Cement. Procedia Manufacturing, 8(October 2016), 635-642. https://doi.org/10.1016/j.promfg.2017.02.081

Puspitawati, Y., \& Rahdriawan, M. (2012). Kajian Pengelolaan Sampah Berbasis Masyarakat dengan Konsep 3R (Reduce, Reuse, Recycle) di Kelurahan Larangan Kota Cirebon. Jurnal Pembangunan Wilayah \& Kota, 8(4), 349. https://doi.org/10.14710/pwk.v8i4.6490

Putra, H. P., \& Yuriandala, Y. (2010). Studi Pemanfaatan Sampah Plastik Menjadi Produk dan Jasa Kreatif. Jurnal Sains \&Teknologi Lingkungan, 2(1), 21-31. https://doi.org/10.20885/jstl.vol2.iss1.art3

Suliyanto (2018). Studi Kelayakan Bisnis Pendekatan Praktis. Penerbit ANDI Yogyakarta.

Saraswati, R. (2015). Pemanfaatan Mikroba Penyubur Tanah sebagai Komponen Teknologi Pertanian. Iptek Tanaman Pangan, 3(1), 41-58.

Sukaraja, C. (2019). Data Profil Desa Desa Sukaraja Tahun 2018 Pemerintah Kabupaten Ciamis.

Sukarno, Z. S., Tinggi, S., Ekonomi, I., \& Bongaya, M. (2019). Menata masyarakat prasejahtera dalam penguatan ekonomi di kota makassar, (August).

Undang-Undang Republik Indonesia Nomor 18 Tahun 2008 Tentang Pengelolaan Sampah. 